\title{
Mixed convection boundary layer flow of a Casson fluid near the stagnation point over a permeable surface
}

\author{
S. P. M. Isa ${ }^{1 *}$, N. M. Arifin² and R. Nazar ${ }^{3}$ \\ ${ }^{I}$ Institute for Mathematical Research, Universiti Putra Malaysia, 43400 UPM Serdang, Selangor, Malaysia \\ ${ }^{2}$ Department of Mathematics, Universiti Putra Malaysia, 43400 UPM Serdang, Selangor, Malaysia \\ ${ }^{3}$ School of Mathematical Sciences, Faculty of Science \& Technology, Universiti Kebangsaan Malaysia, 43600 UKM Bangi, Selangor, Malaysia \\ *Corresponding Author: angau_um@yahoo.com (S.P.M. Isa)
}

Article history :

Received 19 January 2013

Revised 29 May 2013

Accepted 1 July 2013

Available online 1 August 2013

GRAPHICAL ABSTRACT

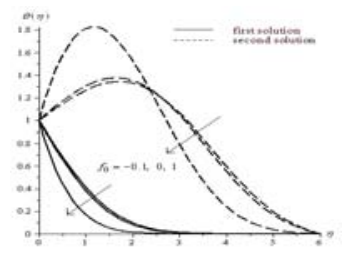

\section{ABSTRACT}

The problem of steady mixed convection boundary layer flow of a Casson fluid near the stagnation-point on a vertical surface when the wall is permeable, where there is suction or injection effect, is considered. The governing partial differential equations are converted into ordinary differential equations by similarity transformation, which is then solved numerically using the shooting method. Results for the skin friction coefficient, local Nusselt number, velocity profiles as well as temperature profiles are presented for different values of the governing parameters. It is found that the imposition of suction is to increase the velocity profiles and to delay the separation of boundary layer, while the injection parameter decreases the velocity profiles.

Keywords: Mixed convection, Boundary layer, Casson Fluid, Suction, Injection

(C) 2014 Penerbit UTM Press. All rights reserved http://dx.doi.org/10.11113/mjfas.v10n1.65

\section{INTRODUCTION}

Heat and mass transfer characteristics about convection of non-Newtonian fluids has attracted many investigations. This is because of its practical engineering applications, such as catalytic reactors (Cohen and Marom [1]), the filtration devices (Holeschovsky and Cooney [2]) and blood plasmaphosresis devices (Beaudoin and Jaffrin [3]). The most popular among non-Newtonian fluids is the Casson (Casson[4]) fluid. Casson fluid are defined as a shear thinning liquid which is assumed to have an infinite viscosity at zero rate of shear, a yield stress below which no flow occurs and a zero viscosity at an infinite rate of shear. The behaviour of blood as a Casson fluid has been studied experimentally by Merill et al. [5] and McDonald [6]. There have been many studies in the literature to better understand the flow characteristics of Casson fluids (Skelland [7], Bird et al. [8], Slattery [9], etc.). There was also review papers discussed on mechanism of heat transfer enhancement for convection heat transfer in nonNewtonian fluid (Denn [10], Rajagopal et al. [11], and Eldabe and Salwa [12]).

The study of boundary layer flow and heat transfer has extensive applications in the field of mechanical engineering. Some numerical studies about a similarity solution on convection boundary layer flow near stagnation point have been considered in the papers by Ramachandran et al. [13], Wang [14-16], Ishak et al. [17,18], Garg and
Rajagopal [19], Hayat et al. [20], etc. The problem of mixed convection boundary layer layer flow of a Casson fluid near the stagnation point has been studied by Isa et al. [21].

The process of suction and blowing has wide applications in many engineering activities such as in the design of thrust bearing and radial diffusers, and thermal oil recovery. Suction is applied to remove reactants on chemical processes. Blowing is used to add reactants, cool the surface, prevent corrosion or scaling and reduce the drag (Labropulu et al. [22]). Hartnett [23] has recognized the significance of suction or injection for the boundary layer control. It is used to postpone separation of the boundary layer to reduce drag and attain high lift values. It is also well known that suction or injection of fluid through the surface, as in mass transfer cooling can significantly modify the flow field. This will affect the rate of heat transfer in forced, free and mixed convection. There are several numerical studies on the effects of uniform suction or injection on the boundary layer flow and heat transfer, by Watanabe and Kawakami [24], Watanabe [25-26] and Pop and Watanabe [27].

Recently, Isa et al. [21] considered the steady mixed convection boundary layer flow of a Casson fluid near the stagnation point. Therefore, the present investigation deals with the steady mixed convection boundary layer flow of a casson fluid over a permeable surface. This study extends the papers by Isa et al. [21] to the case permeable surface 
(considering of suction and injection effects). The transformed ordinary differential equations are solved numerically for some values of the governing parameters. Results are presented in tables and figures showing the effects of the constant suction or injection parameters.

\section{PROBLEM FORMULATION}

Consider the steady two-dimensional flow of a Casson fluid near the stagnation-point on a vertical flat plate of uniform ambient temperature $T_{\infty}$. It is assumed that the velocity distribution far from the surface (potential flow) is given by $u_{e}(x)=a x$, where $a$ is a positive constant. It is also assumed that the temperature of plate is $T_{w}(x)$, where $T_{w}(x)>T_{\infty}$ corresponds to a heated plate (assisting flow) and $T_{w}(x)<T_{\infty}$ corresponds to a cooled plate (opposing flow), respectively. We assume that the rheological equation of state for an isotropic and incompressible flow of a Casson fluid can be written as, see Nakamura and Sawada [28],

$$
\tau_{i j}= \begin{cases}2\left(\mu_{B}+\frac{p_{y}}{\sqrt{2 \pi}}\right) e_{i j}, & \pi>\pi_{c} \\ 2\left(\mu_{B}+\frac{p_{y}}{\sqrt{2 \pi_{c}}}\right) e_{i j}, & \pi<\pi_{c}\end{cases}
$$

where $\pi=e_{i j} e_{i j}$ and $e_{i j}$ is the $(i, j)^{i h}$ component of the deformation rate, $\pi$ is the product of the component of deformation rate with itself, $\pi_{c}$ is a critical value of this product based on the non-Newtonian model, $\mu_{B}$ is plastic dynamic viscosity of the non-Newtonian fluid, and $p_{y}$ is yield stress of fluid. Under these conditions along with the assumption that the viscous dissipation term in the energy equation is taken into consideration, the boundary layer equations which govern this problem are

$$
\begin{gathered}
\frac{\partial u}{\partial x}+\frac{\partial v}{\partial y}=0 \\
u \frac{\partial u}{\partial x}+v \frac{\partial u}{\partial y}=u_{e} \frac{d u_{e}}{d x}+v(1+1 / \beta) \frac{\partial^{2} u}{\partial y^{2}}+g \beta_{T}\left(T-T_{\infty}\right)
\end{gathered}
$$

$$
u \frac{\partial T}{\partial x}+v \frac{\partial T}{\partial y}=\alpha \frac{\partial^{2} T}{\partial y^{2}}
$$

subject to the boundary conditions

$$
\begin{aligned}
& v=v_{w}(x), \quad u=0, \quad T=T_{w}(x)=T_{\infty}+b x \quad \text { at } \quad y=0 \\
& u=u_{e}(x)=a x, \quad T=T_{\infty} \quad \text { as } \quad y \rightarrow \infty
\end{aligned}
$$

where $\alpha$ is the thermal diffusivity, $\beta_{T}$ is the thermal expansion coefficient, $\beta=\mu_{B} \sqrt{2 \pi_{c}} / p_{y}$ is the nonNewtonian (Casson) parameter, $v$ is the kinematic viscosity, $a$ and $b$ is the positive constant and $v_{w}(x)$ is the mass flux velocity with $v_{w}(x)<0$ corresponding to suction and $v_{w}(x)>0$ corresponding to injection or withdrawal fluid, respectively.

We introduce now the following similarity variables

$$
\begin{aligned}
\psi & =\sqrt{a v} x f(\eta), \\
\theta(\eta) & =\left(T-T_{\infty}\right) /\left(T_{w}-T_{\infty}\right), \\
\eta & =\sqrt{a / v} y
\end{aligned}
$$

where $\psi$ is the stream function which is defined in the usual way as $u=\partial \psi / \partial y$ and $v=-\partial \psi / \partial x$. Substituting (6) into Eqs. (3) and (4), the following set of ordinary differential equations results in

$$
(1+1 / \beta) f^{\prime \prime}+f f^{\prime \prime}+1-f^{\prime 2}+\lambda \theta=0
$$

$$
\frac{1}{\operatorname{Pr}} \theta^{\prime \prime}+f \theta^{\prime}-f^{\prime} \theta=0
$$

and the boundary conditions (5) become

$$
\begin{array}{ll}
f(0)=f_{0}, & f^{\prime}(0)=0, \quad \theta(0)=1 \\
f^{\prime}(\infty)=1, & \theta(\infty)=0
\end{array}
$$

where primes denote differentiation with respect to $\eta$, $\operatorname{Pr}=v / \alpha$ is the Prandtl number and $\lambda$ is the mixed convection parameter, which is defined as

$$
\lambda=\frac{G r_{x}}{\operatorname{Re}_{x}^{2}}
$$

with $G r_{x}=g \beta\left(T_{w}-T_{\infty}\right) x^{3} / v^{2}$ being the local Grashof number and $\operatorname{Re}_{x}=u_{e}(x) x / v$ is the local Reynolds number. A non-dimensional constant which determines the transpiration rate is denoted by $f_{0}$, with $f_{0}>0$ for suction and $f_{0}<0$ for blowing or injection. It should be noticed that $\lambda>0$ corresponds to assisting flow, $\lambda<0$ corresponds to opposing flow and $\lambda=0$ corresponds to forced convection flow, respectively. On the other hand, we 
mention that for a regular viscous fluid $(\beta \rightarrow \infty)$, Eq (7) and (8) reduce to Eqs. (6) and (7) from the paper by Ramachandran et al. [13] when $n=1$ and Ishak et al. [18] when $S=0$.

The physical quantities of interest are the skin friction coefficient $C_{f}$ and the local Nusselt number $N u_{x}$, which are defined as

$$
C_{f}=\frac{\tau_{w}}{\rho u_{e}^{2}(x)}, \quad N u_{x}=\frac{x q_{w}}{k\left(T_{w}-T_{\infty}\right)}
$$

where $\tau_{w}$ is the skin friction or shear stress along the stretching surface and $q_{w}$ is the heat flux from the surface, which are given by

$$
\tau_{w}=\mu\left(\frac{\partial u}{\partial y}\right)_{y=0}, \quad q_{w}=-k\left(\frac{\partial T}{\partial y}\right)_{y=0}
$$

Using (6), we get

$$
\operatorname{Re}_{x}^{1 / 2} C_{f}=f^{\prime \prime}(0), \quad \operatorname{Re}_{x}^{-1 / 2} N u_{x}=-\theta^{\prime}(0)
$$

\section{RESULTS \& DISCUSSION}

Equations (7) and (8) subject to boundary conditions (9) have been solved numerically using the shooting method. The results are given to carry out a parametric study showing the influences of the mixed convection parameter $\lambda$, non-Newtonian (Casson) parameter $\beta$ and the suction/injection parameter $f_{0}$.

\begin{tabular}{|c|c|c|c|c|c|c|c|}
\hline \multirow[t]{2}{*}{ Pr } & \multirow[t]{2}{*}{$f(0)$} & \multicolumn{2}{|c|}{$\begin{array}{c}\text { Ramachandran } \\
\text { et al. }\end{array}$} & \multicolumn{2}{|c|}{ Isa et al. } & \multicolumn{2}{|c|}{ Present } \\
\hline & & $f^{\prime \prime}(0)$ & $-\theta^{\prime}(0)$ & $f^{\prime \prime}(0)$ & $-\theta^{\prime}(0)$ & $f^{\prime \prime}(0)$ & $-\theta^{\prime}(0)$ \\
\hline \multirow[t]{3}{*}{0.7} & -0.1 & - & - & - & - & 1.651 & 0.722 \\
\hline & 0 & 1.706 & 0.764 & 1.706 & 0.764 & 1.706 & 0.764 \\
\hline & 1 & - & - & - & - & 2.321 & 1.242 \\
\hline \multirow[t]{3}{*}{7} & -0.1 & - & - & - & - & 1.487 & 1.368 \\
\hline & 0 & 1.518 & 1.722 & 1.518 & 1.722 & 1.518 & 1.722 \\
\hline & 1 & - & - & - & - & 2.008 & 7.362 \\
\hline \multirow[t]{3}{*}{20} & -0.1 & - & - & - & - & 1.436 & 1.545 \\
\hline & 0 & 1.449 & 2.458 & 1.449 & 2.458 & 1.449 & 2.458 \\
\hline & 1 & - & - & - & - & 1.937 & 20.169 \\
\hline \multirow[t]{3}{*}{40} & -0.1 & - & - & - & - & 1.415 & 1.469 \\
\hline & 0 & 1.410 & 3.101 & 1.410 & 3.101 & 1.410 & 3.101 \\
\hline & 1 & - & - & - & - & 1.914 & 40.090 \\
\hline \multirow[t]{3}{*}{60} & -0.1 & - & - & - & - & 1.407 & 1.322 \\
\hline & 0 & 1.390 & 3.551 & 1.390 & 3.552 & 1.390 & 3.551 \\
\hline & 1 & - & - & - & - & 1.906 & 60.061 \\
\hline \multirow[t]{3}{*}{80} & -0.1 & - & - & - & - & 1.404 & 1.176 \\
\hline & 0 & 1.377 & 3.910 & 1.378 & 3.910 & 1.377 & 3.910 \\
\hline & 1 & - & - & - & - & 1.902 & 80.046 \\
\hline \multirow[t]{2}{*}{100} & -0.1 & - & - & - & - & 1.402 & 1.045 \\
\hline & 0 & 1.368 & 4.212 & 1.368 & 4.212 & 1.368 & 4.212 \\
\hline
\end{tabular}

Table 1 Values of $f^{\prime \prime}(0)$ and $-\theta^{\prime}(0)$ for various values of $\operatorname{Pr}$ and $\lambda=1$.
In order to validate the accuracy of the numerical method used, the present results are compared with those of Ramachandran et al. [13] and Isa et al. [21] for the case of impermeable surface $f_{0}=0$, as shown in Table 1 . They are found to be in good agreement. Table 1 also illustrate the influence of the suction $f_{0}=1$ and injection parameter $f_{0}=-0.1$. The results indicate that the imposition of suction at the surface has the tendency to increase the skin friction coefficient $f^{\prime \prime}(0)$ and local Nusselt number $-\theta^{\prime}(0)$, but for the case of surface injection, the skin friction coefficient $f^{\prime \prime}(0)$ and local Nusselt number $-\theta^{\prime}(0)$ decreases.

Variation of skin friction coefficient $f^{\prime \prime}(0)$ with $\lambda$ for different values of non-Newtonian Casson parameter $\beta$ when $\operatorname{Pr}=1$ and $f_{0}=-0.1$ (injection) and 1 (suction) are shown in Figs. 1 and 2, respectively. We also presented the critical value of $\lambda$ (say $\lambda_{c}$ ) in these figures. The results indicate that the imposition of non-Newtonian Casson parameter $\beta$ has the tendency to increase the skin friction coefficient $f^{\prime \prime}(0)$ when $f_{0}=-0.1$ (injection) and 1 (suction). Figure 3 shows the variation of $f^{\prime \prime}(0)$ with $\lambda$ for various values of $f_{0}$ when $\beta=2$ and $\operatorname{Pr}=1$. This figure shows that the suction parameter increases the skin friction coefficient $f^{\prime \prime}(0)$ and the injection parameter decreases the skin friction coefficient. It can be seen that dual solution are also occur in Figs. 1 to 3. As in similar physical situations, we postulate that the upper branch solutions (first solution) are physically stable and occur in practice, whilst the lower branch solutions (second solution) are not physically realizable. This postulate can be verified by performing a stability analysis but this is beyond the scope of the present paper. Figures 4 and 5 depicts the variations of local Nusselt number $-\theta^{\prime}(0)$ with $\lambda$ for various values of $\beta$ when $\operatorname{Pr}=1$ and $f_{0}=-0.1$ (injection) and 1 (suction). In these figures, the dashed line refers to the second (lower branch) solution. So, these solution profiles prove the existence of dual solutions. The results indicate that the increase of the parameter $\beta$ leads to the increase of $-\theta^{\prime}(0)$ with the surface injection. In Fig. 5, the effect of $\beta$ is to increase the value of $-\theta^{\prime}(0)$ for the first solution. The value of $-\theta^{\prime}(0)$ is also increases when $\beta$ is increase for second solution profile when $\lambda<0$ (opposing flow). But, it is seen that the local Nusselt number $-\theta^{\prime}(0)$ decreases with increases of $\beta$ for the second solution when $\lambda>0$ (assisting flow). The variation of the local Nusselt number $-\theta^{\prime}(0)$ with $\lambda$ for various 
values of $f_{0}$ is presented in Fig. 6. From this figure, it is seen that suction parameter increases the value of $-\theta^{\prime}(0)$ and the injection parameter decreases the value of $-\theta^{\prime}(0)$. From Figs. 1 to 6, we have showed that dual solutions exist for assisting flow situations $(\lambda>0)$. However, for opposing flow situations $(\lambda<0)$, there are dual solutions in the range $\lambda_{c}<\lambda<0$, a unique solution for $\lambda=\lambda_{c}$ and no solution for $\lambda<\lambda_{c}$. A unique solution is obtained when first and second solution are connected at point $\lambda=\lambda_{c}$.

The variation of skin friction coefficient and local Nusselt number with $f_{0}$ for different values of $\beta$ when $\operatorname{Pr}=1$ and $\lambda=-1$ are presented in Figs. 7 and 8 . Figure 7 shows that for first solution, when $f_{0} \rightarrow-\infty$, then $f^{\prime \prime}(0) \rightarrow 0$, whereas Fig. 8 presents that when $f_{0} \rightarrow-\infty$, then $-\theta^{\prime}(0) \rightarrow 0$. These indicate that when we consider the first solution, the large injection parameter leads to the small value of skin friction coefficient and local Nusselt number. Figures 7 and 8 also show that for first solution, when $f_{0} \rightarrow+\infty$, then $f^{\prime \prime}(0) \rightarrow+\infty$ and $-\theta^{\prime}(0) \rightarrow+\infty$. From this result, it is found that the skin friction coefficient and local Nusselt number will be increase when suction parameter increases. For the second solution in both figures, the results are opposite to the first solution when $f_{0} \rightarrow+\infty$. So, they show that for second solution, the increase of $f_{0}$ will lead to the decrease of $f^{\prime \prime}(0)$ and $-\theta^{\prime}(0)$. We have observed that dual solutions exist for all values of $f_{0}$. Figures 9 and 10 show the velocity and temperature profiles for different values of $f_{0}$ when $\operatorname{Pr}=1$, $\lambda=-1$ and $\beta=2$. It is found that the imposition of suction is to increase the velocity profiles, while the injection parameter decreases the velocity profiles. Temperature profile is increase with a decrease of suction parameter, and decrease with an increase of injection parameter.

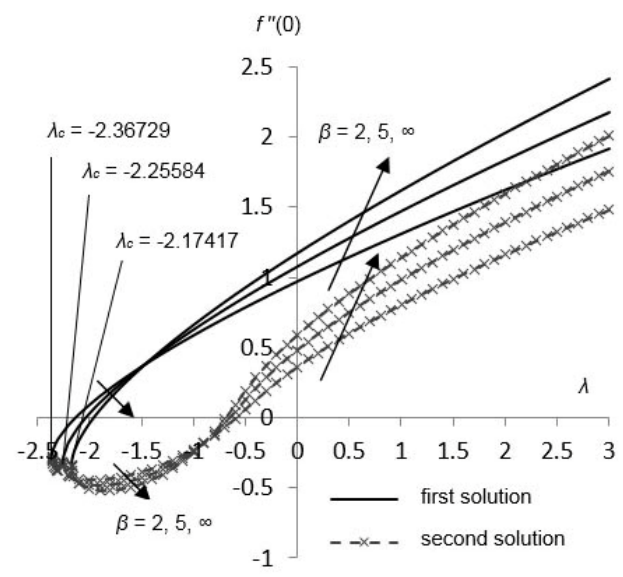

Fig. 1 Variation of the skin friction coefficient with $\lambda$ for different values of $\beta$ when $\operatorname{Pr}=1.0$ and $f_{0}=-0.1$.

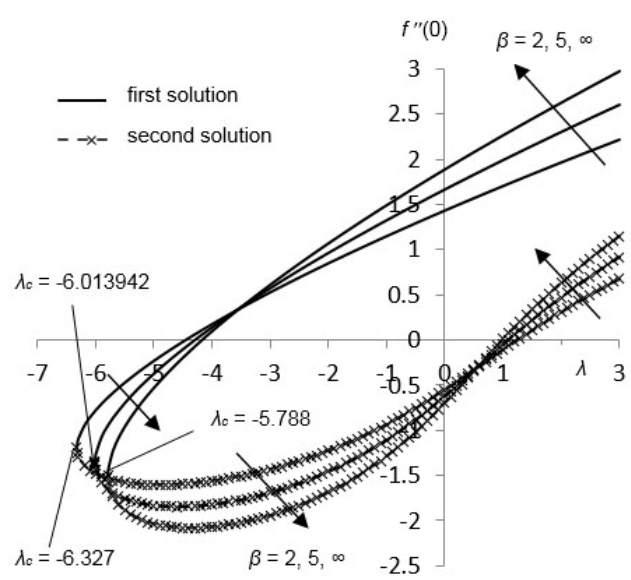

Fig. 2 Variation of the skin friction coefficient with $\lambda$ for different values of $\beta$ when $\operatorname{Pr}=1.0$ and $f_{0}=1$.

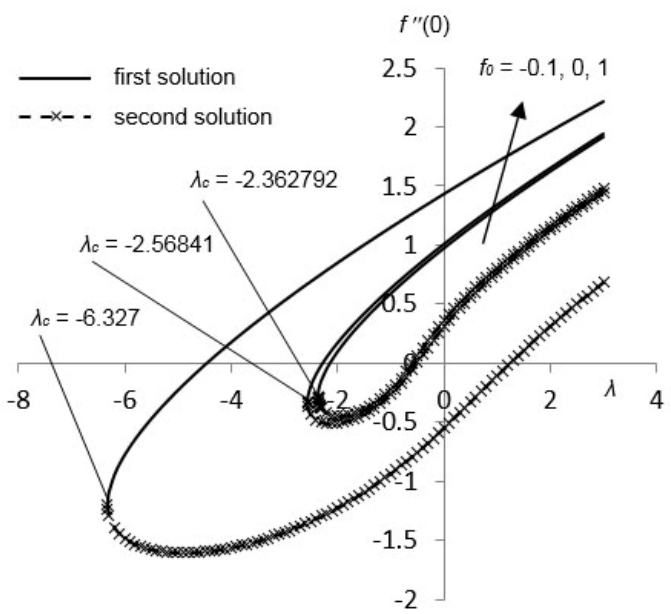

Fig. 3 Variation of the skin friction coefficient with $\lambda$ for different values of $f_{0}$ when $\operatorname{Pr}=1.0$ and $\beta=2$.

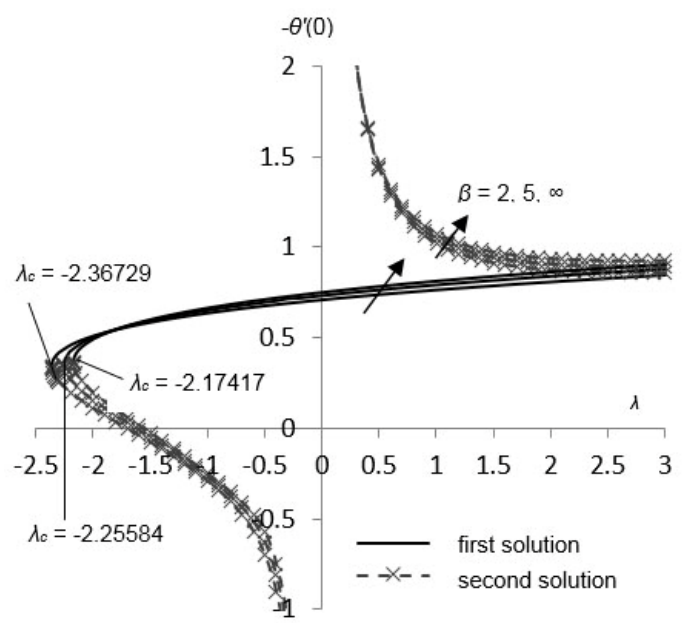


Fig. 4 Variation of the local Nusselt number with $\lambda$ for different values of $\beta$ when $\operatorname{Pr}=1.0$ and $f_{0}=-0.1$.

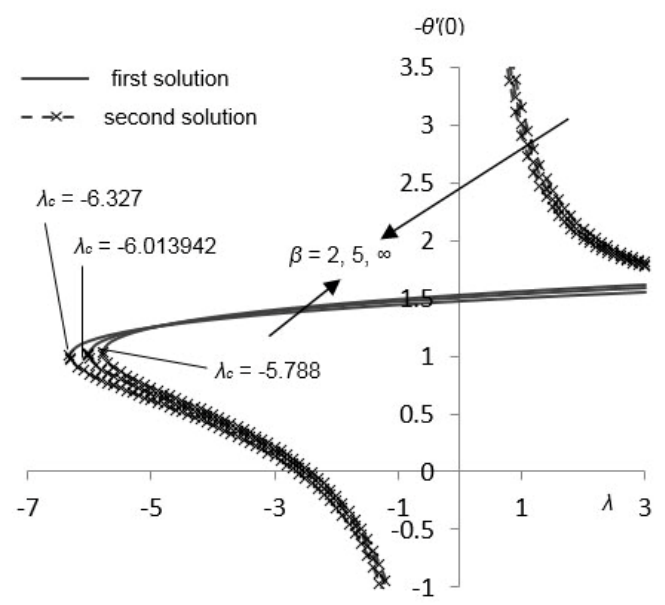

Fig. 5 Variation of the local Nusselt number with $\lambda$ for different values of $\beta$ when $\operatorname{Pr}=1.0$ and $f_{0}=1$.

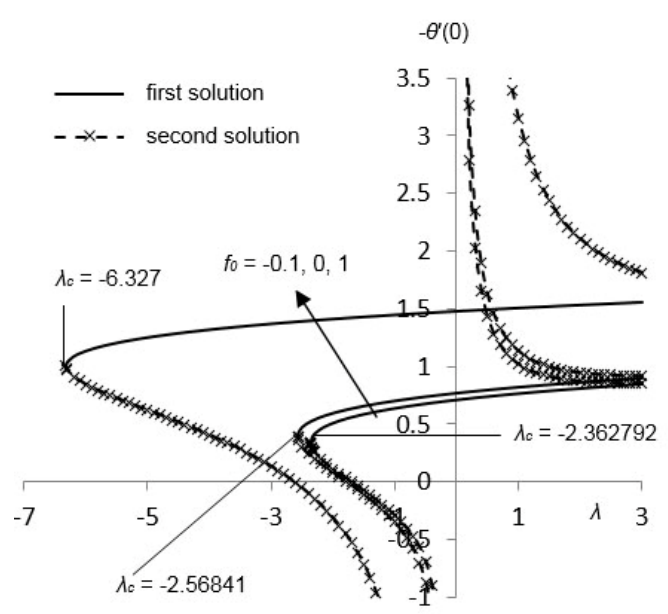

Fig. 6 Variation of the local Nusselt number with $\lambda$ for different values of $f_{0}$ when $\operatorname{Pr}=1.0$ and $\beta=2$.

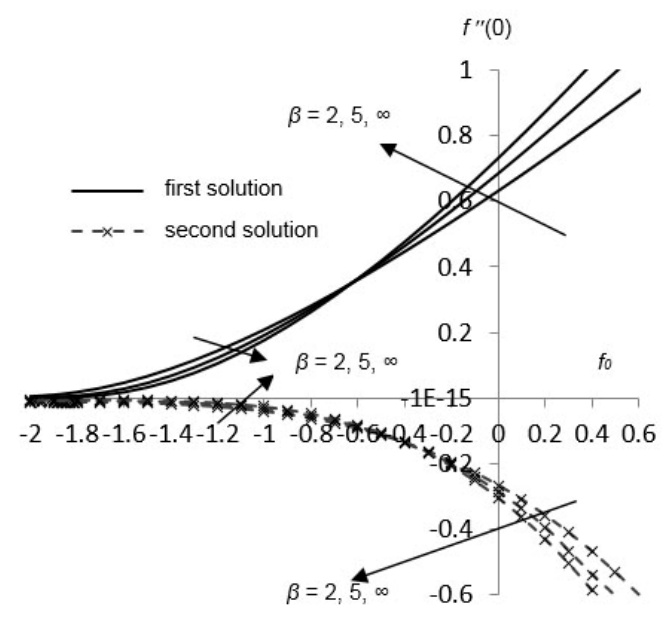

Fig. 7 Variation of the skin friction coefficient with $f_{0}$ for different values of $\beta$ when $\operatorname{Pr}=1$ and $\lambda=-1$.

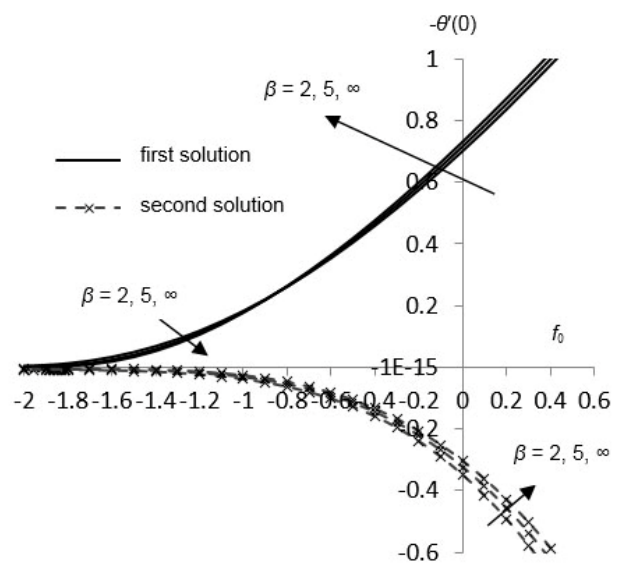

Fig. 8 Variation of the local Nusselt number with $f_{0}$ for different values of $\beta$ when $\operatorname{Pr}=1$ and $\lambda=-1$.

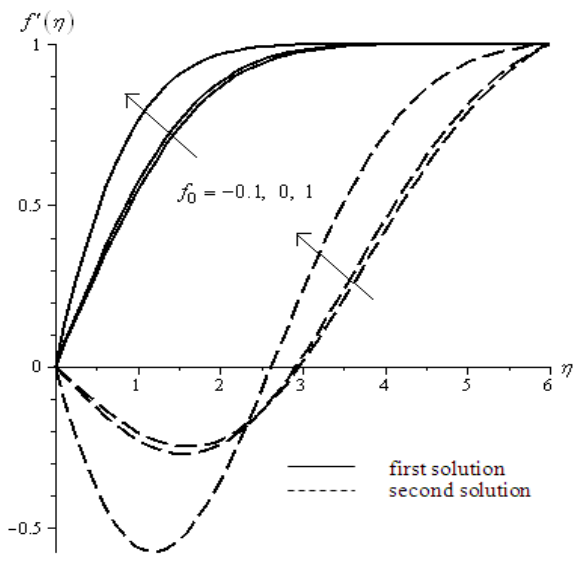

Fig. 9 Velocity profiles for different values of $f_{0}$ when $\operatorname{Pr}=1, \lambda=$ -1 and $\beta=2$. 


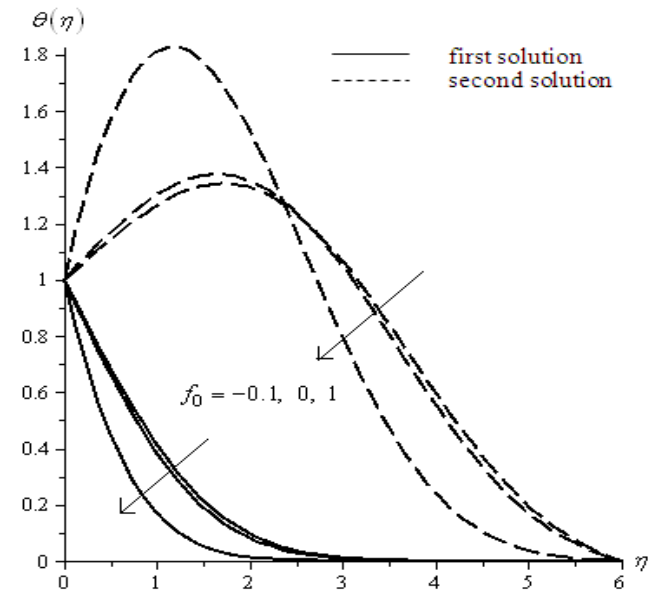

Fig. 10 Temperature profiles for different values of $f_{0}$ when $\operatorname{Pr}=1, \beta=2$ and $\lambda=-1$.

\section{CONCLUSION}

The problem of steady mixed convection boundary layer flow of a Casson fluid near the stagnation-point on a vertical surface when the wall is permeable is studied theoretically. A discussion for the effects of suction or injection parameter $f_{0}$, the mixed convection parameter $\lambda$ on the skin friction coefficient $f^{\prime \prime}(0)$, local Nusselt number $-\theta^{\prime}(0)$, velocity profile $f(\eta)$ and temperature profile $\theta(\eta)$ have been done. We can conclude that imposition of suction is to increase the velocity profiles and to delay the separation of boundary layer, while the injection parameter decreases the velocity profiles. This finding is opposite for temperature profile. On the other hand, when we consider upper branch solution, a very large suction parameter will obtain an increase of skin friction coefficient and local Nusselt number. However, the effect of a large value of injection parameter will reduce skin friction coefficient and local Nusselt number.

\section{ACKNOWLEDGEMENT}

The authors gratefully acknowledgemed the financial support received in the form of a Research University Grant Scheme (RUGS) from Universiti Putra Malaysia.

\section{REFERENCES}

[1] S. Cohen, D.M. Marom, J. Chem. Eng. 27 (1983) 87.

[2] U.B. Holeschovsky, C.L. Cooney, J. AICHE 37 (1991) 1219

[3] G. Beaudoin, M.Y. Jaffrin, Artificial Organs. 13 (1989) 43.

[4] N. Casson, In Rheology of Dispersed System (Edited by C. C. Mill), PergamonPress, Oxford, 1959.

[5] E. W. Merril, A. M. Benis, E. R. Gilliland, T. K. Sherwood, E. W. Salzman, J. Appl.Physiol. 20 (1965) 954.

[6] D. A. McDonald, Blood Flows in Arteries, 2nd Edition, Arnold, London, 1974.

[7] A. H. P. Skelland, Non-Newtonian Flow and Heat Transfer, John Wiley \& Sons, New York, 1966.

[8] R. B. Bird, R. C. Armstrong, O. Hassager, Dynamics of Polymer Liquids ( $2^{\text {nd }}$ edition), Wiley, New York, 1987.

[9] J. C. Slattery, Advanced Transport Phenomena, Cambridge University Press,Cambridge, 1999.

[10] M. M. Denn, Chem. Engng.Sci. 22 (1967) 395.

[11] K. R. Rajagopal, A. S. Gupta, A. S. Wineman, Appl. Sci. Eng. Lett. 18 (1980) 875.

[12] N. T. M. Eldabe, M. G. E. Salwa, J. Phys. Soc. Japan 64 (1995) 4164.

[13] N. Ramachandran, T. S. Chen, B.F. Armaly, ASME J. Heat Transfer 110 (1988) 373.

[14] C. Y. Wang, J. Appl. Math. Phys. 54 (2003) 184.

[15] C. Y. Wang, Chem.Engng. Sci. 61 (2006) 7668.

[16] C. Y. Wang, IMA J. Appl. Math. 72 (2007) 271.

[17] A. Ishak, R. Nazar, I. Pop, Meccanica 41 (2006)509.

[18] A. Ishak, R. Nazar, I. Pop, Int. J. Heat MassTransfer 51 (2008) 3693.

[19] V. K. Garg, K. R. Rajagopal, Mech. Res. Commun. 17 (1990) 415.

[20] T. Hayat, T. Javed, Z. Abbas, Int. J. Heat Mass Transfer51 (2008) 4528.

[21] S. S. P. M. Isa, N. M. Arifin, Mixed convection boundary layer flow of a Casson fluid near the stagnation point, (to be published).

[22] F. Labropulu, J.M. Dorrepaal, O.P. Chandna, Acta Mech. 115 (1996) 15.

[23] J. P. Hartnett, Mass transfer cooling. In: Handbook of Heat Transfer Applications. $2^{\text {nd }}$ ed., W. M. Rohenow, J. P. Hartnett and E. N. Ganic (eds.) Hemisphere, Washington, DC, 1985, 1.

[24] T. Watanabe, H. Kawakami, Trans. Japan Soc. Mech. Eng. 55 (1989) 3365.

[25] T. Watanabe, Acta Mech. 83 (1990) 119.

[26] T. Watanabe, Acta Mech. 89 (1991) 123.

[27] I. Pop and T. Watanabe, TechnischeMechanik 13 (1992) 49.

[28] M. Nakamura, T. Sawada, Journal of Biomechanical Engineering 110 (1988) 137. 